ORIGINALARTICLE

\title{
Renal dysfunction and 30-day mortality risk in patients with acute stroke
}

\author{
Abdulwasiu A Busari', Christiana $\bigcirc$ Amira², Babawale T Bello², Njideka U Okubadejo², Ismail A Abdusalam³, Francis I Ojini² \\ 'Department of Pharmacology, Therapeutics and Toxicology; ${ }^{2}$ Department of Medicine and ${ }^{3}$ Department of Community Health, College \\ of Medicine, University of Lagos, Nigeria.
}

\section{ABSTRACT}

Background: Chronic kidney disease (CKD) and stroke constitute worldwide public health problems with rising incidence, prevalence and poor outcomes. While the link between renal dysfunction and myocardial infarction is well established, the link with stroke has been less well investigated. In this study, the prevalence and prognostic implication of renal dysfunction in patients admitted with acute stroke was assessed.

Methods: This was a prospective observational study of 130 patients with first-ever stroke admitted within 7 days of stroke onset and followed up for 30 days. The study outcome measure was 30-day mortality. Stroke subtype was verified by a computerized tomography (CT) scan of the brain. Estimated glomerular filtration rate (eGFR) was calculated from serum creatinine using the 4-variable Modification of Diet in Renal Disease (MDRD) equation. Renal dysfunction was defined as eGFR $<60 \mathrm{~mL} / \mathrm{min} / 1.73 \mathrm{~m}^{2}$ and significant proteinuria was de fined as urinary protein excretion $\geq 0.5 \mathrm{~g}$ in 24 hours. The Cox proportional hazards regression model was used to determine the relationship between GFR, proteinuria and 30-day mortality.

Results: The majority of the patients studied (56\%) were male and their mean age was $61.3 \pm 13.9$ years. Ischaemic stroke was the most common stroke subtype, accounting for $74 \%$ of all cases. Overall, $38 \%$ of patients had reduced eGFR $<60 \mathrm{~mL} / \mathrm{min} / 1.72 \mathrm{~m}^{2}$ while $35 \%$ had significant proteinuria. eGFR $<60 \mathrm{~mL} / \mathrm{min} / 1.73 \mathrm{~m}^{2}$ (hazard ratio, HR $3.59,95 \% \mathrm{Cl}$ I.03-13.26, $\mathrm{p}<0.00 \mathrm{I})$ and proteinuria ( $\mathrm{HR}$ I.86, Cl I.00-8.14, $\mathrm{p}=0.035)$ were independent predictors of mortality. Other independent predictors were age $>70$ years, haemorrhagic stroke subtype, CNS score $<6.5$ and random blood glucose $>7.8 \mathrm{mmol} / \mathrm{L}$.

Conclusions: Renal dysfunction is common among adult Nigerian patients with acute stroke. Both reduced eGFR and proteinuria were independent predictors of 30-day mortality in these patients.

Keywords: renal dysfunction; chronic kidney disease; proteinuria; stroke; mortality.

\section{INTRODUCTION}

Cardiovascular disease (CVD) is common among patients with chronic kidney disease (CKD) and accounts for about $50 \%$ of the deaths in this group [I]. It has been suggested that patients with CKD are more likely to die from cardiovascular events than they are to progress to end-stage renal disease (ESRD) [2]. This predisposition to adverse cardiovascular outcomes is attributable to the high prevalence of both traditional and non-traditional CVD risk factors seen in patients with CKD [3]. Recently, interest in reduced glomerular filtration rate (GFR) as an independent non-traditional risk factor for CVD and CVD mortality has come to the fore $[4,5]$. Studies suggest that reduced GFR may be an independent risk factor for poor outcomes in patients with myocardial infarction and stroke [6-8]. Yohalom et al. [8], in a prospective study involving 82I Israeli adults with acute stroke, found that reduced GFR was a strong independent predictor of mortality and poor outcomes. Mortality was associated

Received I8 November 2018; accepted 25 April 2019; published 09 May 2019 
with the severity of renal impairment, with individuals in the lowest GFR category (15-44 mL/min/l.73 $\mathrm{m}^{2}$ ) exhibiting a 3-fold increased relative risk of mortality at one year compared with individuals with GFR $>60 \mathrm{~mL} / \mathrm{min} /$ $1.73 \mathrm{~m}^{2}$ [8]. Hao et al. also found that reduced eGFR on admission was a strong predictor of poor outcomes in patients with acute haemorrhagic stroke [9].

Stroke is relatively common in Nigeria and previous studies reported a high 30-day case fatality rate ranging from 4I-60\% [10]. There are, however, limited data available on the association between renal dysfunction and stroke outcomes among Nigerian patients with acute stroke. To provide further data on this association, this study evaluated the relationship between markers of renal dysfunction (reduced GFR and proteinuria) and 30-day mortality in patients admitted with acute stroke at a teaching hospital in Lagos, Nigeria.

\section{METHODS}

This was a prospective, observational study of I 30 consecutive patients with acute stroke admitted into the medical wards of Lagos University Teaching Hospital (LUTH), an 800-bed hospital in Lagos, South-West Nigeria. The hospital provides tertiary care to over 20 million inhabitants of Lagos and its environs. Patients were recruited into the study if they were at least 18 years of age, had experienced a first-ever stroke, presented within 7 days of onset of stroke symptoms and consented to participate in the study. Patients who were experiencing a repeat stroke and those who were pregnant were excluded from the study.

Socio-demographic and clinical information was obtained from study participants using an interviewer-administered questionnaire. Information sought included patients' age, gender, risk factors for stroke including a history of hypertension, diabetes and smoking, and current medications. Each patient underwent a physical examination that was focused on blood pressure measurement, level of consciousness and degree of neurological deficit. The diagnosis of stroke was made in accordance with the World Health Organization (WHO) criteria [10,12], while stroke subtype was confirmed by computerised tomography (CT) scan of the brain. Stroke severity was assessed using the Canadian Neurological Scale (CNS) [12-14]. A blood sample was obtained for complete blood count, serum urea, creatinine, total cholesterol and glucose. A 24-hour sample of urine was collected for determination of urinary protein excretion. GFR was estimated from standardized serum creatinine using the 4-variable Modification of Diet in Renal Disease
(MDRD) equation. Serum creatinine was measured using the Jaffe alkaline picrate method (Hoffmann-La Roche, USA) traceable to isotope dilution mass spectrometry values [15].

All patients were followed up for 30 days post-stroke. The outcome of interest was death within 30 days. The following operational definitions were adopted: reduced GFR was defined as eGFR $<60 \mathrm{~mL} / \mathrm{min} / 1.73 \mathrm{~m}^{2}$ whereas significant proteinuria was defined as urine protein excretion of $\geq 0.5 \mathrm{~g} /$ day. Patients were considered hypertensive if they were previously diagnosed with hypertension or were using antihypertensive medications or had systolic blood pressure $>140 \mathrm{mmHg}$ or diastolic BP $>90 \mathrm{mmHg}$. Diabetes was diagnosed in the presence of hyperglycaemia or the use of oral hypoglycaemic agents or insulin.

Data were analysed using the Statistical Package for Social Sciences $\left(\right.$ SPSS $^{\circledR}$ ) version 21. Categorical variables are presented as percentages while continuous variables are presented as mean \pm standard deviation (SD). Baseline characteristics were compared between participants with eGFR $>60 \mathrm{~mL} / \mathrm{min} / 1.73 \mathrm{~m}^{2}$ and those with eGFR $<60 \mathrm{~mL} /$ $\min / 1.73 \mathrm{~m}^{2}$, those with and those without significant proteinuria, those who were alive at 30 days post-stroke and those who had died during the period. Differences in categorical variables were compared using chi-squared and Fischer's exact tests, and Student's t-test was used to compare numerical variables. The Mann-Whitney test was used for continuous variables not normally distributed. The Cox proportional hazard regression model was used to examine the relationship between eGFR, proteinuria and 30-day mortality. The level of statistical significance was set at a $p$ value $<0.05$.

Ethical approval was granted by the Health Research Ethics Committee (HREC) of Lagos University Teaching Hospital (reference no: ADM/DCST/HREC/I68).

\section{RESULTS}

Of the I 30 participants recruited into the study, 73 (56.2\%) were males. The mean age was 61.3 \pm 13.9 years (range 27-80 years). Figure I shows the age distribution of the study population. The predominant age group was 61-70 years. Table I shows the baseline characteristics of the study population stratified by gender. Most patients (73.8\%) had ischaemic stroke and the mean duration from onset of stroke symptoms to hospital presentation was $2.0 \pm 1.4$ days. Male participants reported a higher frequency of smoking and a higher mean serum creatinine concentration; all other parameters were similar in both genders. 


\begin{tabular}{|c|c|c|c|c|}
\hline Variable & $\begin{array}{c}\text { All patients } \\
n=130 \\
(\text { Mean } \pm \text { SD) }\end{array}$ & $\begin{array}{c}\text { Females } \\
n=57 \\
(\text { Mean } \pm S D)\end{array}$ & $\begin{array}{c}\text { Males } \\
n=73 \\
(\text { Mean } \pm S D)\end{array}$ & P-value \\
\hline Age (years) & $61.3 \pm 13.9$ & $62.5 \pm 13.8$ & $60.4 \pm \mid 4.1$ & 0.397 \\
\hline Duration of symptoms (days) & $2.0 \pm 1.4$ & $2.1 \pm 1.6$ & $1.9 \pm 1.3$ & 0.438 \\
\hline History of hypertension (\%) & I0I (77.7) & $49(85.9)$ & $52(7 \mid .2)$ & 0.057 \\
\hline History of diabetes mellitus (\%) & $16(12.3)$ & $6(10.5)$ & $8(13.7)$ & 1.000 \\
\hline Smoking history (\%) & $10(7.7)$ & $0(0)$ & $10(13.7)$ & 0.010 \\
\hline Systolic BP (mmHg) & $177.6 \pm 32.8$ & $178.4 \pm 27.3$ & $177.0 \pm 36.7$ & 0.810 \\
\hline Diastolic BP (mmHg) & $102.8 \pm 20.9$ & $99.1 \pm 20.6$ & $105.9 \pm 20.8$ & 0.066 \\
\hline Mean arterial pressure $(\mathrm{mmHg})$ & $127.8 \pm 22.2$ & $125.5 \pm 20.3$ & $129.6 \pm 24.8$ & 0.262 \\
\hline \multicolumn{5}{|l|}{ Stroke subtype } \\
\hline Ischaemic (\%) & $96(73.8)$ & $45(78.9)$ & $51(69.9)$ & 0.315 \\
\hline Haemorrhagic (\%) & $34(26.2)$ & $12(21.1)$ & $22(30.1)$ & \\
\hline \multicolumn{5}{|l|}{ CNS scores category (\%) } \\
\hline$<6.5$ & $56(43.1)$ & $28(49.1)$ & $28(38.4)$ & 0.284 \\
\hline$\geq 6.5$ & $74(56.9)$ & $29(50.9)$ & $45(61.6)$ & \\
\hline Haematocrit \% & $34.5 \pm 5.8$ & $34.4 \pm 5.8$ & $34.6 \pm 5.8$ & 0.961 \\
\hline Serum urea $(\mathrm{mmol} / \mathrm{L})$ & $6.6 \pm 2.4$ & $6.3 \pm 2.4$ & $6.8 \pm 2.3$ & 0.230 \\
\hline Creatinine $(\mu \mathrm{mol} / \mathrm{L})$ & $114.9 \pm 44.2$ & $97.2 \pm 44.2$ & $123.8 \pm 44.2$ & 0.001 \\
\hline eGFR $\left(\mathrm{mL} / \mathrm{min} / 1.73 \mathrm{~m}^{2}\right)$ & $70.5 \pm 25.3$ & $69.2 \pm 23.6$ & $71.6 \pm 26.6$ & 0.593 \\
\hline Urine protein $(\mathrm{mg} / 24 \mathrm{hr})$ & $436.8 \pm 276.1$ & $438.5 \pm 286.1$ & $440.2 \pm 264.8$ & 0.972 \\
\hline Random blood glucose (mmol/L) & $7.3 \pm 2.9$ & $7.8 \pm 3.3$ & $6.9 \pm 2.5$ & 0.079 \\
\hline Total cholesterol (mmol/L) & $5.40 \pm 0.66$ & $5.45 \pm 0.65$ & $5.36 \pm 0.66$ & 0.439 \\
\hline
\end{tabular}

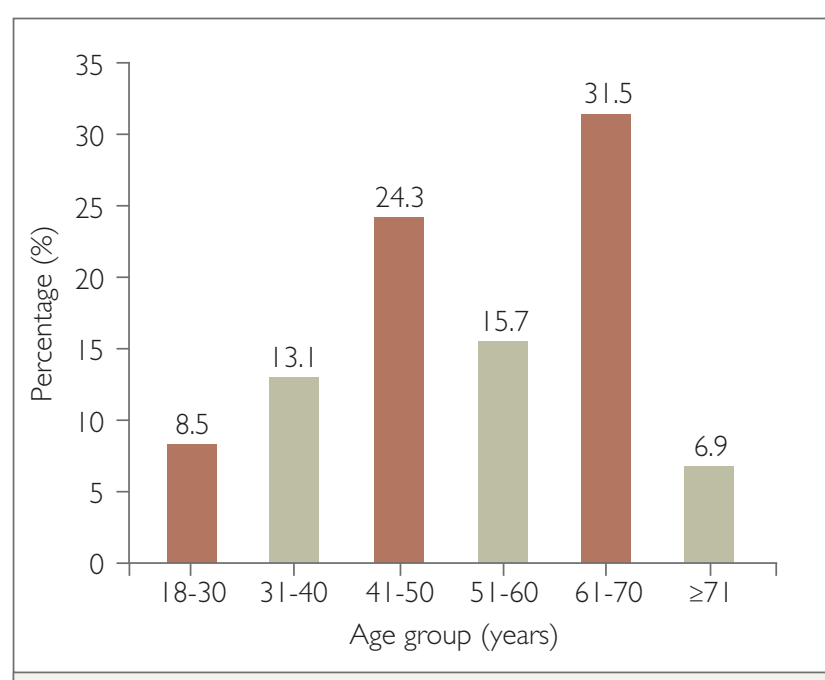

Figure I. Age distribution of the study population.

\section{Clinical presentations in patients with renal dysfunction}

Table 2 shows a comparison of the clinical and laboratory parameters of patients who had reduced eGFR with those with eGFR $>60 \mathrm{~mL} / \mathrm{min} / 1.73 \mathrm{~m}^{2}$. The proportion of patients with low eGFR was $37.7 \%$ and those with significant proteinuria was $35.4 \%$. Patients with reduced eGFR were older, more likely to be female, more likely to be smokers, had worse CNS scores, higher serum urea and lower haematocrit. They also had a higher 30-day mortality compared with the reference group $(73.6 \%$ vs. $10.8 \%$, $\mathrm{p}<0.00 \mathrm{I})$.

Thirty-eight patients died within 30 days of a stroke (mortality rate 29.2\%). Table 3 compares the clinical and laboratory parameters of patients who died with those 
Table 2. Comparison of characteristics of study participants stratified by eGFR.

\begin{tabular}{|c|c|c|c|c|}
\hline Variable & $\begin{array}{c}\text { All patients } \\
n=130 \\
(\text { Mean } \pm \text { SD) }\end{array}$ & $\begin{array}{c}\mathrm{eGFR} \geq 60 \mathrm{~mL} / \\
\mathrm{min} / \mathrm{I} .73 \mathrm{~m}^{2} \\
\mathrm{n}=8 \mathrm{I} \\
(\text { Mean } \pm \mathrm{SD})\end{array}$ & $\begin{array}{c}\mathrm{eGFR} \geq 60 \mathrm{~mL} / \\
\mathrm{min} / \mathrm{I} .73 \mathrm{~m}^{2} \\
\mathrm{n}=49 \\
(\text { Mean } \pm \mathrm{SD})\end{array}$ & P-value \\
\hline Females (\%) & $57(43.8)$ & $20(24.7)$ & $37(75.5)$ & 0.001 \\
\hline Hypertension (\%) & I0I (77.7) & $60(74.1)$ & 41 (83.7) & 0.277 \\
\hline Diabetes mellitus (\%) & $16(12.3)$ & $8(9.9)$ & $8(16.3)$ & 0.286 \\
\hline Current smokers (\%) & $10(7.7)$ & $3(3.7)$ & $7(14.3)$ & 0.041 \\
\hline \multicolumn{5}{|l|}{ Stroke subtype } \\
\hline Ischaemic (\%) & $96(73.8)$ & $64(79.0)$ & $32(65.3)$ & 0.101 \\
\hline Haemorrhagic (\%) & $34(26.2)$ & $17(2 \mid)$ & $17(34.7)$ & \\
\hline \multicolumn{5}{|l|}{ CNS scores category } \\
\hline$<6.5$ & $56(43.1)$ & $29(35.8)$ & $27(55.1)$ & 0.044 \\
\hline$\geq 6.5$ & $74(56.9)$ & $52(64.2)$ & $22(44.9)$ & \\
\hline Duration of symptoms (days) & $2 \pm 1.44$ & $2.1 \pm 1.61$ & $1.9 \pm 1.32$ & 0.465 \\
\hline Systolic BP (mmHg) & $177.6 \pm 32.8$ & $174.6 \pm 30.9$ & $182.6 \pm 35.5$ & 0.178 \\
\hline Diastolic BP (mmHg) & $102.8 \pm 20.9$ & $100.6 \pm 18.5$ & $106.7 \pm 24.2$ & 0.545 \\
\hline Mean arterial pressure $(\mathrm{mmHg})$ & $127.8 \pm 22.2$ & $125.3 \pm 20.4$ & $132.0 \pm 26.3$ & 0.107 \\
\hline Serum urea $(\mathrm{mmol} / \mathrm{L})$ & $6.6 \pm 2.37$ & $5.8 \pm 1.65$ & $7.9 \pm 2.75$ & 0.001 \\
\hline Urine protein (mg/24 hr) & $436.8 \pm 276.1$ & $414.6 \pm 276.7$ & $480.5 \pm 265.1$ & 0.184 \\
\hline Random blood glucose (mmol/L) & $7.3 \pm 2.9$ & $7.4 \pm 3.0$ & $7.3 \pm 2.7$ & 0.849 \\
\hline Total cholesterol (mmol/L) & $5.40 \pm 0.66$ & $5.34 \pm 0.67$ & $5.49 \pm 0.63$ & 0.208 \\
\hline Haematocrit (\%) & $34.5 \pm 5.8$ & $35.8 \pm 5.6$ & $32.4 \pm 5.4$ & 0.001 \\
\hline 30-day mortality rate (\%) & $38(29)$ & $10(10.8)$ & $28(73.6)$ & 0.001 \\
\hline
\end{tabular}

who survived to 30 days. Patients who died were older, more likely to have had haemorrhagic stroke, poor CNS scores, higher RBG, higher total cholesterol, lower eGFR, higher frequency of severe hypertension and proteinuria.

Independent predictors of short-term mortality were advanced age, low eGFR, significant proteinuria and haemorrhagic stroke (Table 4).

\section{DISCUSSION}

There is growing evidence of the relationship between renal dysfunction and cardiovascular morbidity and mortality [2-4]. In this study, $37 \%$ of subjects with acute stroke had renal dysfunction defined as eGFR $<60 \mathrm{~mL} /$ the prevalence of CKD in stroke patients ranges between $28-47 \%[11,16, \mid 7]$. Our finding is comparable to the study by Yahalom et al., who reported a prevalence of $36 \%$ among patients with acute stroke in Israel [16] but differs from the study by $\mathrm{Xu}$ et al. in China, who reported a higher prevalence of $47 \%$ [17]. This higher prevalence may be explained by the fact that $X u$ et al. included subjects in all five CKD stages and not just those with GFR $<60 \mathrm{~mL} / \mathrm{min} / 1.73 \mathrm{~m}^{2}$ [17].

About one-third of our participants had significant proteinuria. This differs from the study by $\mathrm{Xu}$ et al., who reported a prevalence of microalbuminuria and proteinuria of $11.2 \%$ and $24.8 \%$, respectively [ 17 ]. In that study, microalbuminuria was determined by measuring the albuminto-creatinine ratio (ACR) in spot urine samples whereas proteinuria was determined semi-quantitatively by routine 
Table 3. Comparison of clinical characteristics of stroke patients who died within 30 days with those who survived.

\begin{tabular}{|c|c|c|c|c|}
\hline Variable & $\begin{array}{c}\text { All patients } \\
n=130 \\
(\text { Mean } \pm S D)\end{array}$ & $\begin{array}{c}\text { Survived } \\
n=92 \\
(\text { Mean } \pm S D)\end{array}$ & $\begin{array}{c}\text { Died } \\
n=38 \\
(\text { Mean } \pm S D)\end{array}$ & P-value \\
\hline Age (years) & $61.3 \pm 13.9$ & $57.3 \pm 12.6$ & $71.1 \pm 12.3$ & 0.001 \\
\hline Females (\%) & $57(43.8)$ & $39(42.4)$ & $18(47.4)$ & 0.524 \\
\hline Hypertension (\%) & I0I (77.7) & $69(75)$ & $32(84.2)$ & 0.350 \\
\hline \multicolumn{5}{|l|}{ Stroke subtype } \\
\hline Haemorrhagic (\%) & $34(26.2)$ & $17(18.5)$ & $17(44.7)$ & 0.004 \\
\hline \multicolumn{5}{|l|}{ CNS scores category } \\
\hline$<6.5$ & $56(43.1)$ & $27(29.3)$ & $29(76.3)$ & 0.000 \\
\hline Duration of symptoms (days) & $2.0 \pm 1.4$ & $2.1 \pm 1.61$ & $1.9 \pm 1.3$ & 0.500 \\
\hline Mean arterial pressure $(\mathrm{mmHg})$ & $127.8 \pm 22.2$ & $127.5 \pm 20.8$ & $128.6 \pm 27.7$ & 0.805 \\
\hline Serum urea (mmol/L) & $6.6 \pm 2.4$ & $6.15 \pm 1.97$ & $7.67 \pm 2.86$ & 0.001 \\
\hline Creatinine $(\mu \mathrm{mol} / \mathrm{L})$ & $114.9 \pm 44.2$ & $1 \mid 6.7 \pm 40.7$ & $151.2 \pm 49.5$ & 0.000 \\
\hline Urine protein (mg/24 hr) & $436.8 \pm 276.1$ & $416.5 \pm 264.9$ & $494.9 \pm 288.4$ & 0.137 \\
\hline Random blood glucose (mmol/L) & $7.3 \pm 2.9$ & $6.8 \pm 1.9$ & $8.7 \pm 4.2$ & 0.001 \\
\hline Total cholesterol (mmol/L) & $5.40 \pm 0.66$ & $5.27 \pm 0.52$ & $5.70 \pm 0.84$ & 0.000 \\
\hline Haematocrit (\%) & $34.5 \pm 5.8$ & $34.9 \pm 5.5$ & $33.6 \pm 6.3$ & 0.243 \\
\hline $\mathrm{eGFR}<60 \mathrm{~mL} / \mathrm{min} / 1.73 \mathrm{~m}^{2}(\%)$ & $49(37.7)$ & $21(22.8)$ & $28(73.7)$ & 0.000 \\
\hline Proteinuria > 500 mg/24 hours (\%) & $46(35.4)$ & $27(29.3)$ & $19(50)$ & 0.029 \\
\hline Proportion with severely elevated BP (\%) & $83(63.8)$ & $64(69.6)$ & $19(50)$ & 0.045 \\
\hline
\end{tabular}

Table 4. Cox proportional hazards model for predictors of 30-days mortality.

\begin{tabular}{|c|c|c|c|}
\hline Variable & $\mathrm{HR}$ & $\mathrm{Cl} 95 \%$ & P-value \\
\hline Age $>70$ years & 4.25 & $5.12-57.07$ & 0.001 \\
\hline GCS $<8$ & 0.45 & $0.03-6.18$ & 0.828 \\
\hline CNS $<6.5$ & 3.61 & $0.86-15.15$ & 0.048 \\
\hline Haemorrhagic stroke & 2.00 & $2.09-19.65$ & 0.009 \\
\hline $\mathrm{GFR}<60 \mathrm{~mL} / \mathrm{min} / 1.73 \mathrm{~m}^{2}$ & 3.59 & $1.03-13.26$ & 0.001 \\
\hline Urine protein $>0.5 \mathrm{~g} / 24 \mathrm{hr}$ & 1.86 & $1.00-8.14$ & 0.035 \\
\hline RBG $>140 \mathrm{mg} / \mathrm{dL}(>7.8 \mathrm{mmol} / \mathrm{L})$ & 4.54 & $1.27-16.29$ & 0.020 \\
\hline
\end{tabular}

urinalysis. Unlike the study by $\mathrm{Xu}$ et al., which used the ACR on spot urine samples, we collected 24-hour urine samples to determine total protein excretion.

We observed that reduced GFR and proteinuria were have found an association between renal dysfunction and poor cardiovascular outcomes $[9,11,16,17,18]$. Tsahalis et al. reported that renal dysfunction is an independent prognostic factor for mortality and new cardiovascular morbidity in acute stroke [II]. Similarly, Hao et al., in 
China, found that reduced eGFR on admission was a strong predictor of poor outcomes for acute stroke [9]. Yahalom et al. assessed the association between baseline eGFR and I-year outcomes in 82 I consecutive patients with acute stroke and found that CKD was present in $36 \%$ of their patients. eGFR $<45 \mathrm{~mL} / \mathrm{min} / 1.73 \mathrm{~m}^{2}$ was a strong independent predictor of mortality and poor outcomes, whereas milder reductions in GFR (> $45 \mathrm{~mL} /$ $\mathrm{min} / 1.73 \mathrm{~m}^{2}$ ) was not associated with mortality [16]. The mechanism by which renal dysfunction is associated with poor outcomes would include a higher prevalence of both traditional and non-traditional cardiovascular risk factors $[17,19,20]$. In our study, the prevalence of hypertension was relatively high. Hypertension is a strong risk factor for stroke, especially among Blacks. Black patients with hypertension have a 1.3 times greater rate of nonfatal stroke and 1.8 times greater rate of fatal stroke [7,2। ]. Similarly, the majority of the subjects had anaemia, one of the non-traditional cardiovascular risk factors. The prevalence of anaemia increases as GFR declines $[16,19,20]$.

Our study also found that proteinuria was associated with an increased risk of death in acute stroke, as previously reported in other studies $[11,18]$. Significant proteinuria is indicative of more severe kidney damage and this may explain the poor outcomes seen with proteinuric CKD. This finding is comparable to the study by Ovbiagele et al. in the United States, who reported that among ischaemic stroke patients without known CKD, proteinuria on admission was independently linked with lower odds of going home directly from the hospital, and a poorer functional status upon discharge [22]. This was corroborated in the study by $X u$ et al. [17]. Similarly, preliminary results of the Kidney Early Evaluation Program (KEEP) found that eGFR $<60 \mathrm{~mL} / \mathrm{min} / 1.73 \mathrm{~m}^{2}$ or urine albumin:creatinine ratio $>30$ was associated with poorer outcomes in myocardial infarction or stroke [23]. In that study, a poor CNS score, high level of RBG, haemorrhagic stroke subtype and advanced age were also associated with increased risk of death. Chambers et al. also reported that advanced age was a predictor of short-term mortality in acute stroke [24]. Furthermore, Colombo et al. showed that haemorrhagic stroke and advanced age were the predictors of mortality in 503 stroke patients [25]. The Besançon stroke registry in France indicated that among 2500 consecutive patients with stroke, independent predictors of poor outcome were age $>70$ years, hyperglycaemia and female gender [26]. Censori et al., in Italy, showed that a Canadian Neurological Scale score $<6.5$ at entry was associated with significant handicap or death at 30 days [27]. A Nigerian study reported furthermore that glycaemia, haemorrhagic stroke, DBP, aspiration pneumonia, raised intracranial pressure and NIHSS score $>20$ [28].

Our study has some limitations. GFR was assessed using prediction equations rather than by gold standard methods of measurement [29]. Second, it was conducted in a single centre. Larger, multicentre studies are required to confirm our findings. Lastly, since we had no renal function data prior to the stroke suffered by our patients, the low GFR may have developed subsequent to dehydration following the stroke. This, however, is unlikely in our centre as our treatment protocol emphasizes rehydrating all patients who present with acute stroke.

\section{CONCLUSIONS}

Reduced GFR and proteinuria, which are indices of renal dysfunction, are strong predictors of 30-day mortality after acute stroke. We recommend that all patients with acute stroke be screened routinely for evidence of renal dysfunction.

\section{Acknowledgement}

We thank Professor MA Danesi, former Head of the Department of Medicine of the College of Medicine, University of Lagos, for his useful comments and support.

\section{REFERENCES}

I. Levey AS, Coresh J, Balk E, Kausz AT, Levin A, Steffes MW, et al. National Kidney Foundation practice guidelines for chronic kidney disease: Evaluation, classification, and stratification. Ann Intern Med. 2003; 139(2): | 37-147.

2. Alani H, Tamimi A, Tamimi N. Cardiovascular co-morbidity in chronic kidney disease: Current knowledge and future research needs. World J Nephrol. 20 I4; 3(4): 156-I68.

3. Sarnak MJ, Levey AS, Schoolwerth AC, Coresh J, Culleton B, Hamm LL, et al. Kidney disease as a risk factor for development of cardiovascular disease. Hypertension. 2003; 42: I 050- 1065.

4. Herzog CA, Asinger RW, Berger AK. Cardiovascular disease in chronic kidney disease. A clinical update from Kidney Disease: Improving Global Outcomes (KDIGO). Kidney Int. 20I I; 80:572-586.

5. Zhang R, Zheng L, Sun Z. Decreased glomerular filtration rate is associated with mortality and cardiovascular events in patients with hypertension: a prospective study. PLoS ONE. 201 I; 6:e27359-e27359.

6. Satoh $H$, Ishimori N, Sakakibara M, Yamada S, Kawashima N, Urasawa K, et al. Decreased glomerular filtration rate is a significant and independent risk for in-hospital mortality in Japanese patients with acute myocardial infarction: report from the Hokkaido acute myocardial infarction registry. Hypertension Research. 20। 2; 35:463-469.

7. Lee M, Saver JL, Chang KH, Liao HW, Chang SC, Ovbiagele B. Low glomerular filtration rate and risk of stroke: meta-analysis. BMJ. 2010; $341: c 4249-c 4249$.

8. Yahalom G, Schwartz R, Schwammenthal Y, Merzeliak O, Toashi M, Orion D, et al. Chronic kidney disease and clinical outcome in patients with acute stroke. Stroke. 2009; 40:1296-I303. 
9. Hao Z, Wu B, Lin S, Kong FY, Tao WD, Wang DR, et al. Association between renal function and clinical outcome in patients with acute stroke. Eur Neurol. 2010; 63:237-242.

10. Ogun SA, Oluwole O, Fatade B, Ogunseyinde AO, Ojini Fl, Odusote KA. Comparison of Siriraj Stroke Score and the WHO criteria in the clinical classification of stroke subtypes. Afr J Med Med Sci. 2002; 31 (1):13-16.

I।. Tsagalis G, Akrivos T, Alevizaki M, Manios E, Stamatellopoulos K, Laggouranis A, et al. Renal dysfunction in acute stroke: an independent predictor of long-term all combined vascular events and overall mortality. Nephrol Dial Transplant. 2009; 24:194-200.

12. Tareen N, Zadshir A, Martins D, Pan D. Nicholas S, Norris K Chronic kidney disease in African American and Mexican American populations. Kidney Int. 2005; 68(Suppl 97):SI 37- 140.

13. Bushnell CD, Johnston DC, Goldstein LB. Retrospective assessment of initial stroke severity. Comparison of the NIH Stroke Scale and the Canadian Neurological Scale. Stroke. 2001; 32:656-66I.

14. Côté R, Hachinski VC, Shurvell BL, Norris JW, Wolfson C. The Canadian Neurological Scale: a preliminary study in acute stroke. Stroke. 1986; 17(4):731-737.

15. Romero J, Bover J, Fite J, Bellmunt S, Dilmé J, Camacho M, Vila L, Jose-Román Escudero J. The modification of diet in renal disease 4-calculated glomerular filtration rate is a better prognostic factor of cardiovascular events than classical cardiovascular risk factors in patients with peripheral arterial disease. J Vasc Surg. 2012; 56(5): | 324- 1330.

16. Yahalom G, Schwartz R, Schwammenthal Y, Merzeliak O, Toashi M, Orion D, et al. Chronic kidney disease and clinical outcome in patients with acute stroke. Stroke. 2009; 40: I 296-I 303.

17. Xu J, Wang W, Shi H, Chen S, Liu Z, Li W, et al. Chronic kidney disease is prevalent in Chinese patients admitted with verified cerebrovascular lesions and predicts short-term prognosis. Nephrol Dial Transplant. 20। I; ।: I-5.

18. Zhang C, Wang X, He M, Qin X, Tang G, Xu X, et al. Proteinuria is an independent risk factor for first incident stroke in adults under treatment for hypertension in China. J Am Heart Assoc. 2015; 4(I 2): e002639.

19. McCullough PA, Jurkovitz CT, Pergola PE, McGill JB, Brown WW, Collins AJ, et al. Independent components of chronic kidney disease as a cardiovascular risk state: results from the Kidney Early Evaluation Program (KEEP). Arch Intern Med. 2007; 167:1 I 22-1 I 29.

20. Johnson DW, Armstrong K, Campbell SB, Mudge DW, Hawley CM, Coombes JS, et al. Metabolic syndrome in severe chronic kidney disease: prevalence, predictors, prognostic significance and effects of risk factor modification. Nephrology (Carlton). 2007; 12:39|-398.

21. Ferdinand KC, Armani AM. The management of hypertension in African Americans. Crit Pathw Cardiol. 2007; 6(2):67-7I.

22. Ovbiagele B, Sanossian N, Liebeskind DS, Kim D, Ali LK, Pineda S, et al. Indices of kidney dysfunction and discharge outcomes in hospitalized stroke patients without known renal disease. Cerebrovasc Dis. 2009; 28:582-588.

23. Parikh NI, Hwang SJ, Larson MG, Meigs JB, Levy D, Fox CS. Cardiovascular disease risk factors in chronic kidney disease Overall burden and rates of treatment and control. Arch Intern Med. 2006; | 66: | 884-|89|

24. Chambers BR, Norris JW, Shurvell BC, Hachinski VC. Prognosis of acute stroke. Neurology. 1987; 37:221-225.

25. Colombo A, Faglioni P, Morzullom SM, Soqurto P. Risk factors and short-term prognosis in ischaemic and haemorrhagic attacks. Review of 503 patients admitted to neurology clinic of Modena. Neurology 1989; 59: $1-7$

26. Moullin T, Tatu L, Chavot D. Besancon Stroke Registry. An acute stroke registry of 2500 consecutive patients. Eur. Neurol. 1997; 38: 10-20
27. Censori B, Camerlingo M, Casto L, Ferraro B, Gazzaniga GC, Cesana $B$, et al. Prognostic factors in first-ever stroke in the carotid artery territory seen within 6 hours after onset. Stroke 1993; 24:532-535.

28. Mustapha AF, Ogunniyi OA, Sanya EO. Acute stroke at the University College Hospital Ibadan, Nigeria: Clinical profile and predictors of 30-day mortality. Niger Med Pract. 20 I I; 59:3-I0.

29. Smith HW. The reliability of inulin as a measure of glomerular filtration. In: The kidney: structure and function in health and disease. New York: Oxford University Press; 1951. pp. 231-238. 